\title{
Avaliação Dimensional de Troquéis de Gesso Obtidos de Moldes de Hidrocolóide Irreversível após Desinfecção
}

\section{Dimensional Evaluation of Stone Die from Irreversíble Hydrocolloid Impression afther Disinfection}

\author{
Paulo Roberto Boer ${ }^{1}$; Paulo Afonso S. Francisconi²; Marcos Frossard ${ }^{3}$ \\ Resumo
}

\begin{abstract}
Nos procedimentos de moldagens, rotineiramente executados em Odontologia, os materiais entram em contacto com fluidos bucais, como: sangue, saliva, exudatos e outros que podem conter microorganismos patogênicos e, pelos moldes, podem transmitir doenças infecto-contagiosas como: herpes, hepatite, tuberculose, AIDS, dentre outras. O tratamento por imersão desses moldes em substâncias químicas, tem sido adotado no sentido de promover a desinfecção dos mesmos. Este trabalho avaliou a alteração dimensional de troquéis de gesso obtidos de moldes de hidrocolóide irreversível (alginato), após desinfecção. Utilizou-se, para isso, um dispositivo de moldagem que contém um troquel-padrão metálico, representando um dente preparado para receber uma coroa. Após a obtenção dos moldes, os mesmos foram imersos em água deionizada e solução de glutaraldeido a $2 \%$ por 30 minutos. Um grupo que serviu de controle não foi imerso, sendo o mesmo vazado em gesso especial tipo IV (Durone), imediatamente após a sua obtenção. Foi utilizada uma coroa padrão metálica que se adaptava aos referidos troquéis de gesso, para a avaliação dimensional dos mesmos. Esse conjunto, troquel de gesso mais coroa-padrão foi levado para leitura em um microscópio de profundidade. Os dados obtidos dessa mensuração foram submetidos a análise estatística, e os resultados demonstraram não haver diferença estatisticamente significante entre os grupos estudados.
\end{abstract}

Palavras-chave: Avaliação dimensional. Molde. Desinfecção.

\begin{abstract}
During routine molding procedures in Dentistry, the material gets in touch with oral fluids such as blood, saliva, exudates and others, which can carry pathogenic microorganisms that cause contagious diseases such us herpes, hepatitis, tuberculosis, AIDS, among others. Disinfection by immersing the molds in chemical solutions has been adopted. This work evaluated dimensional alterations in casts obtained from an irreversible hydrocolloid, after disinfection. A molding device with a standard metallic die representing the tooth ready to receive the crown was used during the evaluation. The molds were then immersed in deionized water and gluteraldehyde at $2 \%$ for 30 minutes. Only the control group was not immersed: they were poured in a special type IV (Durone), immediately after being taken. A special standard metallic crown, which adapted itself to the referred casts, was used to evaluate their dimensions. The combination die plus standard crown was submitted to a microscopic analysis by a depth microscope. Data from the evaluation were submitted to a statistical analysis, and the results showed no statistically difference among the groups studied.
\end{abstract}

Key words: Dimensional evaluation. Mold. Disinfection.

\footnotetext{
1 Prof. Mestre de Prótese Fixa e Oclusão, do Departamento de Odontologia Restauradora, do Centro de Ciências da Saúde - UEL - E-mail: boerpr@hotmail.com

2 Prof. Dr. de Materiais Dentários da Faculdade de Odontologia de Bauru - USP.

3 Prof. Dr. de Prótese Fixa e Oclusão, do Departamento de Odontologia Restauradora, do Centro de Ciências da Saúde - UEL.
} 


\section{Introdução}

O primeiro relato de obtenção de um molde da boca ocorreu em 1756, quando Pfaff descreveu um procedimento no qual se usava cera de abelha como material de moldagem (PHILLIPS, 1993). Sabemos que nos procedimentos de moldagens, os materiais utilizados entram em contato com os fluidos bucais como sangue, saliva, exudatos e outros, e que esses podem conter microorganismos patogênicos, podendo, via moldes, transmitir doenças infectocontagiosas como herpes, hepatite, tuberculose, AIDS etc.

Preocupado com a questão da biossegurança, há necessidade de criarmos métodos de desinfecção desses moldes. Com a impossibilidade dos moldes serem esterilizados, por ser este método danoso aos materiais de moldagens, procedimentos como desinfecção por imersão, por meio de substâncias químicas, têm sido considerados os mais eficazes.

Como tem preconizado a ADA (American Dental Association), os moldes devem ser lavados em água corrente para a remoção de detritos, sangue e saliva, e depois desinfetados por imersão em soluções químicas que sejam compatíveis com os materiais de moldagem (AMERICAN DENTAL ASSOCIATION, 1996).

Ciente da importância e complexidade da prevenção de doenças infecto-contagiosas e, sabendo que a fidelidade dimensional e de reprodução de detalhes anatômicos são importantes requisitos para um molde usado na confecção de modelos de gesso e troquéis, entendemos ser interessante investigar se a imersão em soluções químicas desinfetantes produz algum tipo de alteração quanto à fidelidade dimensional dos mesmos.

Notamos, na literatura recente, uma falta de consenso entre os pesquisadores quanto aos resultados observados no tocante à estabilidade dimensional desses materiais de moldagens, após a desinfecção.

O propósito deste trabalho foi avaliar se moldes de hidrocolóide irreversível (alginato) podem ser desinfetados em solução química como glutaraldeido a $2 \%$ por 30 minutos, sem que haja alteração dimensional dos mesmos.

\section{Materiais e Métodos}

Foram utilizados para o desenvolvimento desta pesquisa um hidrocolóide irreversível (Jeltrate), água deionizada, solução química desinfetante (glutaraldeido a 2\%). Para a obtenção dos troquéis de gesso, utilizouse um gesso pedra especial tipo IV (Durone).

Um dispositivo descrito por Araújo e Jorgensen (1985), (como mostra a figura 1), foi utilizado para a realização das moldagens. Ele é constituído de duas plataformas: uma inferior, denominada de base, na qual é fixada a moldeira, e outra superior, chamada de parte móvel do dispositivo, na qual é preso o troquel metálico, utilizado como padrão e fixado à parte móvel por intermédio do parafuso fixador do troquel. O troquel-padrão, torneado em aço inoxidável, com formato tronco-cônico, simula um dente preparado para receber uma coroa total.

Uma coroa-padrão, igualmente confeccionada em aço inoxidável, servirá para comparar as dimensões dos futuros troquéis de gesso com o troquel-padrão. Ela é cortada na sua parte oclusal, em altura para coincider precisamente com a face oclusal do troquel, e apresenta em sua parte interna, dimensões tais que se encaixa com justeza no troquel-padrão. Isso significa que, se este troquel estiver com a face oclusal voltada para cima, o plano desta sua face se encontrará na exata altura da superfície oclusal cortada da coroa, desde que exista padronização do posicionamento dessa coroa no troquel. Próximo à borda do troquel, na sua face oclusal, existe uma depressão (marca) chamada convencionalmente de 12 horas. Na coroa-padrão também existem marcas (depressões): a marca das 12 horas é dupla e há outras três marcas únicas nas regiões de 3, 6, 9 horas. Considera-se posicionada e ajustada a coroa-padrão, quando a marca (única) do troquel (a qual corresponde às 12 horas) estiver alinhada com a dupla marca (depressões) da coroa-padrão e o centro 
imaginário da face oclusal do troquel; a figura 2 mostra a coroa-padrão adaptada ao troquel-padrão metálico.

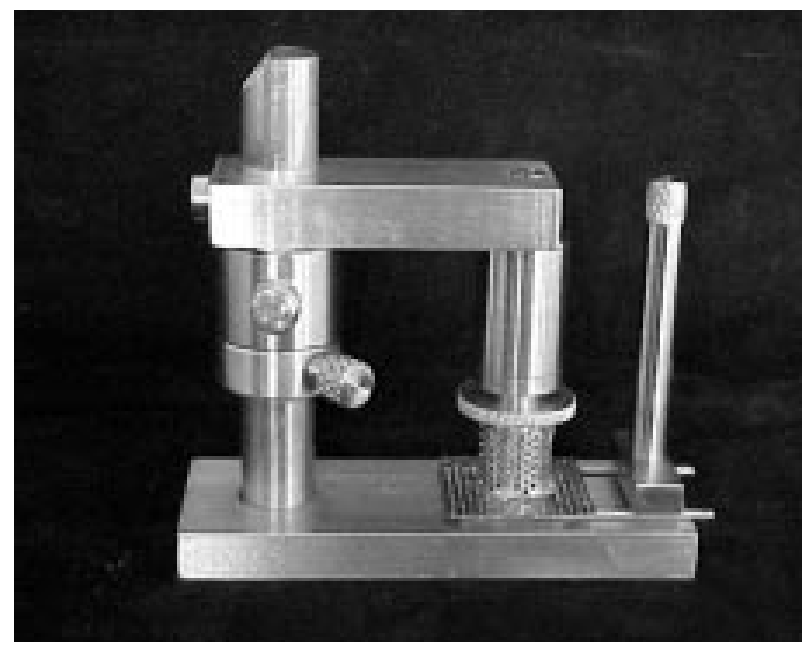

Figura 1. Dispositivo de moldagem.

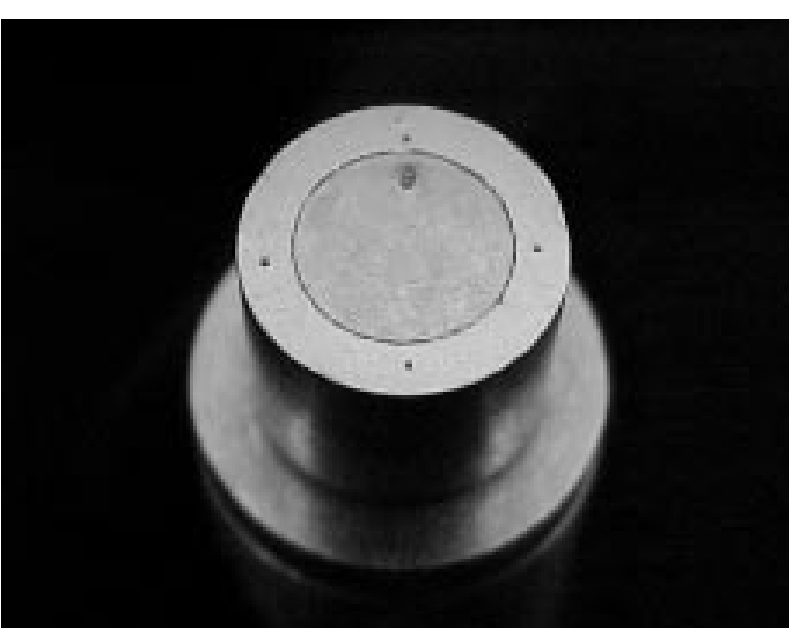

Figura 2. Coroa-padrão metálica adaptada ao troquelpadrão metálico.

Quando da moldagem com o alginato,o dispositivo foi ajustado da seguinte maneira: o cilindro centralizador foi adaptado ao troquel-padrão metálico e, quando deslizado para baixo, a haste vertical ajustava o cilindro centralizador ao interior da moldeira, que se encontrava solta, até seu posicionamento definitivo. Isso ocorreu quando o cilindro centralizador tocava o fundo da moldeira: neste momento, fixou-se a moldeira à base com um parafuso que a imobilizava, prendendo as duas hastes que nela existiam soldadas à sua base.
$\mathrm{O}$ anel de manutenção de altura, em que se encontrava encaixada a citada haste vertical, foi então elevado até tocar no anel da plataforma superior, onde foi fixado por um parafuso enquanto se mantinham as plataformas imóveis.

Como continente dos materiais de moldagem, as moldeiras cilíndricas foram confeccionadas com aço inoxidável e galvanizadas para evitar que sofressem reação pela substância desinfetante, e com furos em todas as paredes, que serviam para reter o material de moldagem. As moldeiras apresentam como medidas, na parte interna, $10 \mathrm{~mm}$, tanto na altura quanto no diâmetro, proporcionando uma espessura para o material de moldagem, de $2 \mathrm{~mm}$ na região do equador, e de $4 \mathrm{~mm}$ na região oclusal.

\section{Obtenção dos Moldes}

Os procedimentos de moldagens foram executados em laboratório com controle de temperatura e umidade: temperatura de $23^{\circ} \mathrm{C} \pm 1^{\circ} \mathrm{C}$ e umidade relativa do ar de $50 \% \pm 5 \%$.

Para a utilização do alginato foi dosado, seguindo as orientações do fabricante, o que correspondeu a 7,5 g do pó do alginato. Esse material foi pesado em uma balança de alta precisão da marca Sartórios e colocado sobre 19,00 ml de água deionizada, medida com seringa, sendo a espatulação executada manualmente por 45 segundos, como preconiza o fabricante.

As misturas resultantes, em quantidade suficientes para obtenção do molde, foram colocadas primeiramente parte da mistura, sobre o troquelpadrão metálico e o restante do alginato no interior da moldeira. Neste momento, procedeu-se à colocação da plataforma superior, que era adequadamente encaixada na haste cilíndrica e baixada até que tocasse no anel de manutenção de altura, que já se encontrava firmemente fixado. Durante esta operação, como o troquel-padrão fazia parte deste sistema, aquele foi concomitantemente introduzido de forma adequada no interior da moldeira. Procedeu-se então, à imobilização da plataforma superior com o auxílio de um parafuso. 
Aguardou-se por 10 minutos (contados a partir do início da mistura) para a geleificação do material. Para que o troquel-padrão fosse separado do molde, este era deixado em repouso por 5 minutos sobre uma bancada, para liberação de tensões induzidas. Após este período, procedia-se aos passos subsequentes, ou seja, o tratamento dos moldes e obtenção dos modelos de gesso (troquéis).

\section{Tratamento dos Moldes}

Conforme os procedimentos de moldagens descritos anteriormente, foram obtidos 30 moldes, dos quais 10 não sofreram tratamento (imersão) e foram chamados grupo de controle (seco); 10 foram imersos em água deionizada por 30 minutos, chamados grupo controle (úmido); e os outros 10 moldes foram imersos em solução de glutaraldeido a $2 \%$ por 30 minutos. A solução utilizada para o tratamento dos moldes era preparada a fresco, observando-se rigorosamente a data de vencimento.

A solução de glutaraldeido a $2 \%$, foi colocada no interior de um recipiente de vidro $(100 \mathrm{ml})$. Após o molde ser imerso em seu interior, este conjunto foi coberto com uma tampa de vidro para evitar a liberação de gás e alteração da sua concentração; um desses moldes pode ser visto na figura 3. Aguardaram-se 30 minutos e removeu-se o molde, que foi lavado por 20 segundos em água deionizada e posteriormente secos com jatos de ar também por 20 segundos com seringa tríplice. Após estes procedimentos, ao molde foi então vertido gesso especial.

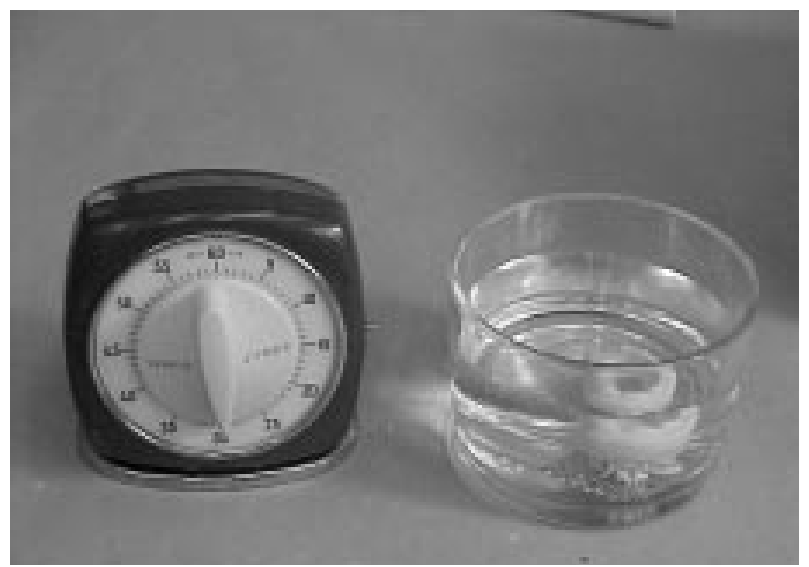

Figura 3. Molde imerso em solução desinfetante, por 30 minutos.
O mesmo tipo de recipiente, também foi utilizado para a imersão de moldes em água deionizada e tratados nas mesmas condições estabelecidas para as situações anteriores, configurando o grupo controle (úmido).

\section{Confecção dos Troquéis}

$\mathrm{Na}$ sequência dos procedimentos descritos anteriormente, efetuou-se a confecção dos troquéis, com gesso pedra do tipo IV (Durone). Para essa confecção se empregou $4 \mathrm{~g}$ de gesso, pesado em uma balança eletrônica da marca Sartórios - Werke Ag - Germany, e colocado sobre $1 \mathrm{ml}$ de água deionizada, medida com pipeta. A espatulação foi executada manualmente, por 60 segundos, como preconiza o fabricante.

A mistura resultante, em quantidade suficiente para a obtenção do troquel de gesso, foi então vertida no molde, sempre em pequenas quantidades, e sob vibração constante, até o seu completo preenchimento. Para verter o gesso no molde, foi utilizado um pincel de n. 2-266.

Aguardaram-se 120 minutos, desde o início da mistura, para que então o troquel de gesso fosse separado do respectivo molde. A seguir esse troquel foi guardado em um recipiente hermético, no qual aguardaria a data de leitura (como veremos adiante).

Somente foi confeccionado um novo troquel quando um novo molde estivesse pronto. Foram obtidos, dessa maneira 30 troquéis: 10 para cada grupo experimental; na figura 4, podemos ver um dos troquéis obtidos.

\section{Medições dos Troquéis}

Após 14 dias da confecção dos troquéis de gesso, estes foram levados para medição, que consistia na aferição da adaptação da coroa-padrão ao troquel de gesso, feito em um microscópio de profundidade. Como podemos ver na figura 5 , foi utilizado um dispositivo chamado verticulador, cuja função era 
nivelar a face oclusal dos troquéis, antes da leitura no referido microscópio.

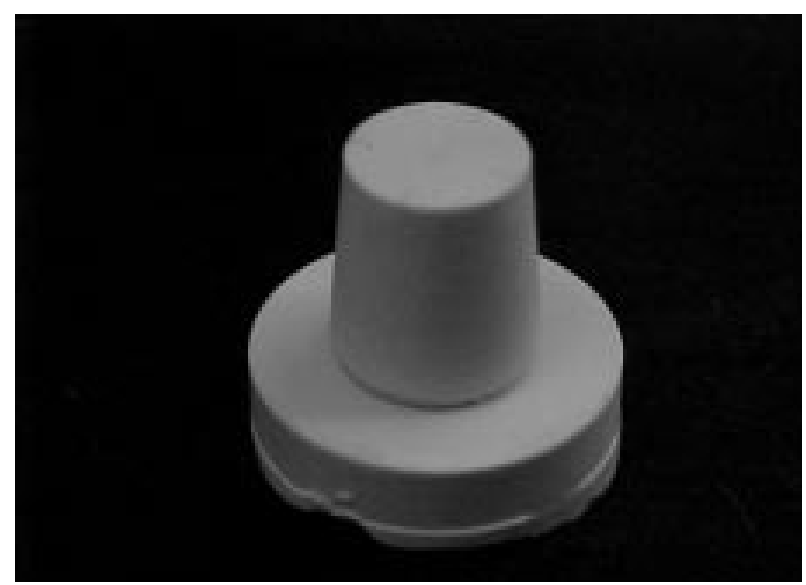

Figura 4. Um dos troquéis obtidos.

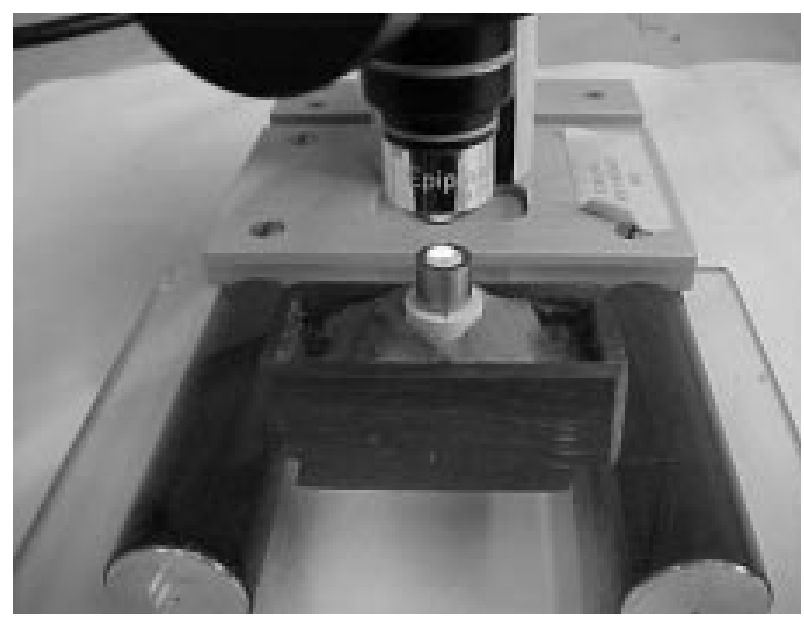

Figura 5. Troquel com a coroa metálica posicionado na base do microscópio pronto para leitura.

Para a medição, sempre foram feitas três leituras para cada região (12, 03, 06, 09 horas). A média foi anotada em uma tabela, para futura comparação com os valores semelhantes obtidos com o troquel padrão, e levados também para análise estatística.

\section{Resultado e Discussão}

O resultado da média da leitura da adaptação da coroa-padrão nos 10 troquéis de gesso obtidos, para os grupos estudados, e os desvios padrão, encontrase na tabela 1 e gráfico 1 .
Tabela 1. Médias e desvios padrão dos grupos experimentais analisados, em micrômetros.

\begin{tabular}{|l|c|c|}
\hline \multicolumn{1}{|c|}{ Tratamento } & media & dp \\
\hline Controle (seco) & 110,24 & 35,45 \\
\hline Controle (umido) & 121,63 & 105,82 \\
\hline Glutaraldeido & 134,31 & 69,28 \\
\hline
\end{tabular}

Grafico 1. Média, desvio padrão das condições experimentais, em micrometros.

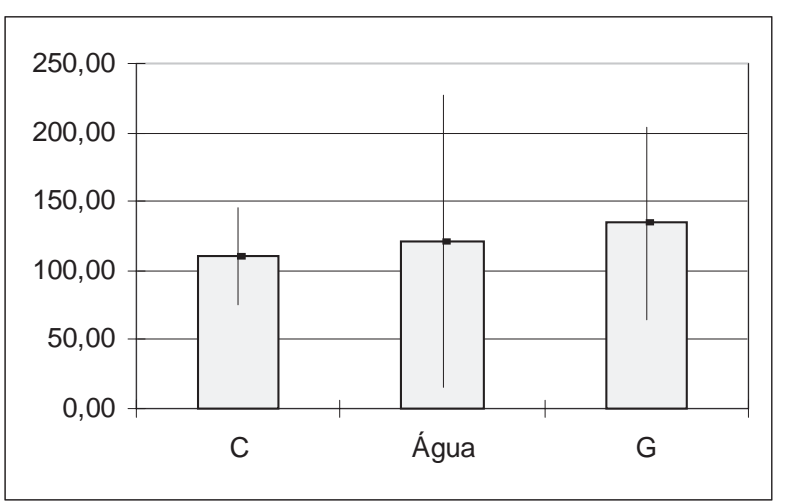

Como os dados não passaram pelo critério de homocedasticidade (homogeneidade de variância), para a comparação entre os grupos foi utilizado o teste não paramétrico de Kruskal-Wallis (ZAR, 1996). O teste mostrou não haver diferença estatisticamente significante entre os grupos $(H=1,19 ; \mathrm{p}=0,551)$.

Quanto ao resultado da avaliação dimensional, nota-se, pela revisão de literatura, que existem vários métodos para se fazer esta avaliação e, diante disto, deve-se buscar um método que facilite a compreensão dos resultados e sua aplicação clínica.

A estabilidade dimensional é testada pela comparação com medidas de um modelo ou troquelpadrão (STACKHOUSE JR, 1975). Esta propriedade tem sido medida por grande variedade de instrumentos, em inúmeros estudos.

Diferenças estatisticamente significantes no resultado da avaliação da alteração dimensional devem ser traduzidas em significância clínica (OWEN, 1993). 
Pelos resultados obtidos, pode-se notar que o material estudado não sofreu alteração dimensional, observada nas leituras da adaptação da coroa-padrão aos troquéis de gesso, quando comparados com o grupo controle seco e grupo controle úmido.

Vários são os fatores que podem afetar a precisão dimensional dos moldes obtidos com os diferentes materiais de moldagem, tais como: espessura do material de moldagem (ARAÚJO, 1985; ASGAR, 1971; BLOMBERG, 1992; PHILLIPS, 1993), adesão à moldeira (ASGAR, 1971; PHILLIPS, 1993), direcionamento da contração de polimerização do material de moldagem (ASGAR, 1971; BLOMBERG, 1992), tempo de polimerização e vazamento do molde (BLOMBERG, 1992), entre outros.

Diante disso, podemos notar que várias são as influências que um material de moldagem pode sofrer durante e após a confecção do molde, o que contribui, de alguma maneira, para as suas alterações dimensionais. Outro fator que também se deve considerar, é o que se refere aos tratamentos dos moldes em soluções desinfetantes, ou seja, desinfecção por substâncias químicas.

Os resultados obtidos neste trabalho, comparados com os de outros autores (OWEN, 1993; HERRERA, 1986; STACKHOUSE JR, 1975) que também avaliaram o mesmo material após imersão de 30 minutos, em soluções desinfetantes de glutaraldeido a $2 \%$, nem foram os mesmos.

Esse fato vem demonstrar que, essas diferenças de resultados podem estar associadas a uma série de fatores, como relata Owen et al. (1993). Nesse trabalho, o citado autor observa que soluções utilizadas em desinfecção podem afetar a qualidade dos materiais de moldagem, alterando os detalhes de reprodução de superfície, aspereza e estabilidade dimensional. Conclui Owen et al. (1993), quando o método de desinfecção dos hidrocolóides irreversíveis for por imersão, poderá produzir resultados não previsíveis.

Segundo os autores desses estudos, algumas contradições podem ser explicadas por diferenças de métodos e avaliações, e outras, por diferenças de marcas do mesmo material.

\section{Conclusões}

Com base nos resultados deste estudo, as seguintes conclusões podem ser obtidas:

A imersão do alginato em solução de glutaraldeido a $2 \%$, por 30 minutos, produziram troquéis de gesso sem alteração dimensional estatisticamente significante, quando comparado ao grupo controle (seco) e ao grupo controle (úmido).

\section{Referências}

AMERICAN DENTAL ASSOCIATION. Infection control recomendationes for the dental office and the dental laboratory. Journal of the American Dental Association, Chicago, v.127, p.672-80, may 1996.

ARAÚJO, P. A.; JORGENSEN, K. D. Effect of material bulk and undercuts on the accuracy of impression materials. The Journal of Prosthetic Dentistry, Saint Louis, v.54, n.6, p.791-4, dec.1985.

ARAÚJO, P. A. et al. Viscoelastics properties of setting elastomeric impression materials. The Journal of Prosthetic Dentistry, Saint Louis, v.54, n.5, p.633-6, nov. 1985.

ASGAR, K. Elastic impression materials. Dental Clinics of North America, Philadelphia, v.15, n.1, p.81-98, jan. 1971.

BLOMBERG, P. A. H. et al. Some parameters for testing deformation of elastomeric impression materials. Australian Dental Journal, North Sydney, v.37, n.4, p.271-276, 1992.

HERRERA, S. P. et al. Dimensional stability of dental impressions after immersion disinfection. Journal of the American Dental Association, SãoPaulo, v.113, p.419-422, sept. 1986.

OWEN, C. P. et al. Disinfection of impression materials to prevent viral cross contamination: a review and a protocol. The International Journal of Prosthodontics, Lombard, v.6, n.5, p.480-494, 1993.

PHILLIPS, R. W. Skinner materiais dentários. 9. ed. Rio de Janeiro: Guanabara Koogan, 1993.

STACKHOUSE JR., J. A. A. Comparacion of elastic impression materials. The Journal of Prosthetic Dentistry, Saint Louis, v.34, n.3, p.305-313, sept. 1975.

ZAR, J. H. Biostatistical analysis. 3. ed. New Jersey: Prentice - Hall, 1996. 